\title{
Sobrevivencia y crecimiento de post-larvas de Argopecten purpuratus (Lamarck, 1819) en Bahía Inglesa, Chile: efectos del origen, distribución en la bahía y bacterioflora larval
}

\author{
Postlarval survival and growth of Argopecten purpuratus (Lamarck,1819) in Bahia \\ Inglesa, Chile: effects of origin, distribution in the bay and larval bacterioflora
}

RUBÉN E. AVENDAÑO ${ }^{1}$, CARLOS E. RIQUELME¹, RUBÉN ESCRIBANO² \& NELSON REYES ${ }^{3}$

\begin{abstract}
${ }^{1}$ Departamento de Acuicultura, Facultad de Recursos del Mar, Universidad de Antofagasta, Casilla 170, Antofagasta, Chile, e-mail: criquelme@uantof.cl

${ }^{2}$ Instituto de Investigaciones Oceanológicas, Facultad de Recursos del Mar, Universidad de Antofagasta, Casilla 170, Antofagasta, Chile

${ }^{3}$ Cultivos Marinos Internacionales S.A.
\end{abstract}

\begin{abstract}
RESUMEN
Argopecten purpuratus es uno de los recursos marinos de mayor importancia comercial en Chile. Una de las etapas críticas en el cultivo de esta especie, es el traspaso de las post-larvas al medio natural, ya que durante este período se produce un significativo descenso en el número de post-larvas. Los factores que provocan estas bajas sobrevivencias pueden ser diversos, pero aún son desconocidos. En el presente estudio se evaluó la incidencia en la sobrevivencia y crecimiento de las variables origen de las larvas, distribución de los colectores en diferentes estaciones de Bahía Inglesa, III región (27 $03^{\prime} 24^{\prime \prime} \mathrm{S}, 70^{\circ} 51^{\prime} 30^{\prime \prime} \mathrm{O}$ ) y los cambios en la bacterioflora asociadas a las post-larvas. Los organismos utilizados en el estudio fueron obtenidas desde los "hatcheries" de Cultivos Marinos Internacionales (III región) y Cultivos Guayacán (IV región). Los resultados del estudio indican claramente que la ubicación y origen de las postlarvas en la bahía incide en la sobrevivencia de éstas. Sin embargo, el crecimiento no es afectado por las variables estudiadas $(\mathrm{P}<0,05)$. Desde un punto de vista microbiológico se observa que Vibrio spp. llega a ser un componente predominante en la microflora de ambas poblaciones larvales alcanzando porcentajes de 53,36 \%. El análisis de componentes principales revela que no hay diferencias entre los Vibrio spp. cultivables de ambos cultivos. No obstante, la microflora residente de las larvas de Guayacánes más estable a los incrementos de bacterias del medio circundante.
\end{abstract}

Palabras clave: Argopecten purpuratus, sobrevivencia y crecimiento post-larval, Vibrio spp.

\begin{abstract}
Argopecten purpuratus is one of the most commercially important marine resources in Chile. One of the most critical steps in the massive culture of this species is the transference of postlarvae from hatchery production to the sea where significant mortality regularly occurs. The factors behind this low survival rate are probably diverse, and are as yet unknown. In the present study, postlarval survival and growth was observed as a function of origin of postlarvae, distribution of postlarvae in the bay, and microbial loading of the postlarvae. Survival rates were measured for different

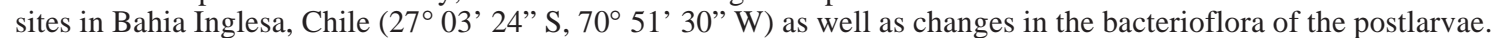
Postlarvae utilized in the study were obtained from Cultivos Marinos Internacionales (III Región) and Cultivos Guayacan (IV Región). Results of the study clearly indicated that survival in culture of the postlarvae was related to their location in the bay and the origin of the postlarvae. However, the growth of the post-larvae is not affected $(\mathrm{P}<$ 0.05). Microbiologically, it was observed that Vibrio spp. were the bacterial component most represented among strains isolated from the postlarvae $(53.36 \%)$ from both populations studied. Principal component analysis revealed no differences between cultivable vibrios from both cultures. However, microflora from the Guayacan group were less susceptible to increases in bacteria originating in their surrounding environment.
\end{abstract}

Key words: Argopecten purpuratus, postlarval survival and growth, Vibrio spp. 


\section{INTRODUCCIÓN}

El ostión del norte Argopecten purpuratus (Mollusca: Pectinidae), es una especie que se distribuye geográficamente desde las costas de Nicaragua $\left(12^{\circ} 40^{\prime} \mathrm{N}\right)$ hasta Valparaíso $\left(36^{\circ} 40^{\prime}\right.$ S), Chile (Uriarte et al. 1996). En Chile las poblaciones se distribuyen en forma discontinua, concentrándose entre las zonas de Antofagasta $\left(23^{\circ}\right.$ $\left.25^{\prime} \mathrm{S}\right)$ y Coquimbo $\left(30^{\circ} \mathrm{S}\right)$ (Avendaño \& Cantillanez 1996).

Desde hace dos décadas este recurso ha tenido una fuerte demanda, situación que ha generado un incremento en el esfuerzo pesquero, causando la explotación clandestina de los bancos naturales y sobreexplotación del recurso (Wolff \& Alarcón 1993, Avendaño \& Cantillanez 1997).

De esta forma el desarrollo del cultivo de esta especie ha sido de vital importancia para preservar este organismo y sustentar la actividad comercial del recurso. No obstante, la producción artificial de A. purpuratus aún es baja para la gran demanda internacional de pectínidos (Ávila et al. 1994), ya que más del $70 \%$ de la producción chilena de ostiones aún viene de colecta de semillas desde el medio natural (Farías et al. 1998).

Actualmente, la producción artificial se basa en la existencia de nueve semilleros, siendo Cultivos Marinos Internacionales S.A. el mayor productor de semillas de nuestro país y el hemisferio sur (Compendio de Acuicultura 1998, Anónimo 2000). Sin embargo, en el cultivo de $A$. purpuratus existen numerosas etapas críticas que impiden a los acuicultores lograr un éxito completo en la producción de semillas. Una de estas etapas es el traspaso de las post-larvas al medio natural, ya que durante este período se produce un significativo descenso en el número de postlarvas. En este contexto diversos son los factores que provocan la mortalidad de moluscos bivalvos en el medio ambiente, entre ellos se encuentran la cantidad y calidad del alimento, aparición de microorganismos patógenos, cambios en los factores abióticos y condiciones locales de las corrientes (Winter 1978, Navarro et al. 1991, Disalvo 1991' ${ }^{1}$, Lodeiros et al. 2000).

Sin embargo, no existe información si la sobrevivencia y crecimiento de las post-larvas esta determinada por la localización de éstas en la bahía. En este contexto es vital para la producción del pectínido conocer los lugares óptimos en la bahía del punto de vista de sobrevivencia y creci-

${ }^{1}$ DISALVO L (1991) Vibriosis y problemas de cultivo del Ostión (Argopecten purpuratus). Cuarto Congreso Latinoamericano de Ciencias del Mar, Coquimbo, Chile. 172 pp. miento post-larval. De igual modo, es interesante conocer la bacterioflora post-larval particularmente Vibrio spp. y determinar si estas bacterias permanecen como microflora nativa durante el desarrollo de pre-engorda o fluctúan debido a las condiciones ambientales.

Los objetivos del presente estudio fueron evaluar la sobrevivencia y crecimiento de post-larvas de A. purpuratus en diferentes sitios de Bahía Inglesa y determinar los cambios en la bacterioflora asociada a larvas provenientes de diferentes centros de cultivo.

\section{MATERIALES Y MÉTODOS}

\section{Área de estudio}

El estudio fue realizado entre enero y marzo de 1999, en Bahía Inglesa (2703' 24” S, $70^{\circ} 51^{\prime}$ 30 "' O), área concesionada a Cultivos Marinos Internacionales S.A. e Hidrocultivos S.A., ambas empresas dedicadas al cultivo de A. purpuratus. Se fijaron cinco estaciones en la bahía para la distribución de los colectores (Fig.1A). La estación E5 corresponde al lugar utilizado por los cultivadores para disponer los colectores.

Con el objeto de estimar las variaciones de la temperatura y conducta del fitopláncton de la bahía, se consideró una estación de referencia ubicada en el centro de la bahía (PB). Para los registros periódicos de temperatura se utilizó un detector de oxígeno disuelto (OTI ORION Model 830). La abundancia fitoplanctónica del agua a $10 \mathrm{~m}$ de profundidad se determinó mediante el método de Utermöhl (1958). Cabe destacar que se considero la profundidad de $10 \mathrm{~m}$, ya que a esta profundidad se disponen los sistemas de cultivos.

\section{Cultivo larvario}

Larvas velígeres de 17 días de cultivo se obtuvieron a partir de reproductores provenientes de los hatcheries de CMI y Cultivos Guayacán (IV región). Las larvas de cultivos Guayacán fueron transportadas en botellas con agua de mar filtrada a $10 \mu \mathrm{m}$ al "hatchery" de CMI (aproximadamente a $500 \mathrm{~km}$ de distancia). Las larvas se mantuvieron por $48 \mathrm{~h}$ bajo condiciones controladas en un estanque cilíndrico de $5.000 \mathrm{~L}$. Durante este período de acondicionamiento, el agua fue cambiada diariamente y las larvas se alimentaron una vez al día con una mezcla de Isochrysis galbana (Clone T-ISO), Chaetoceros gracilis y Chaetoceros calcitrans en una concentración final de 2,5 x $10^{4}$ 
células $\mathrm{ml}^{-1}$. En similares condiciones fueron mantenidas las larvas producidas en CMI.

\section{Cultivo post-larval}

Las "larvas con ojo" fueron trasladadas a estanques de fibra de vidrio de $3.000 \mathrm{~L}$, en una densidad de 1 larva $\mathrm{ml}^{-1}$. Colectores de netlón de $150 \mathrm{x}$ $30 \mathrm{~cm}$, previamente biologizados fueron colocados en los estanques que contenían las larvas de CMI y Guayacán, separadamente. En esta etapa de fijación las larvas permanecieron durante 6 días y se alimentaron con una dieta de 7.500 células $\mathrm{ml}^{-1}$ de $C$. calcitrans y 10.000 células $\mathrm{ml}^{-}$ ${ }^{1}$ de $C$. gracilis. Al séptimo día los colectores fueron embolsados en mallas y agrupados en reinales, los cuales quedaron en los estanques con agua circulando. Luego, las post-larvas de ambos

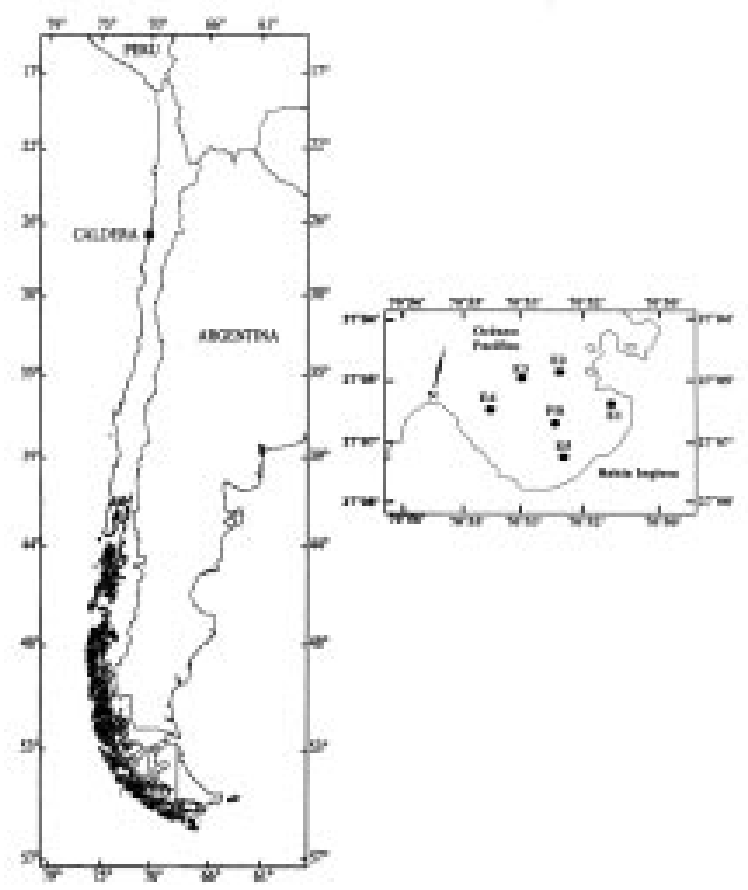

Fig. 1: (A) Área de estudio. Localización de las estaciones E1, E2, E3, E4 y E5, en las cuales fueron colocados los colectores en Bahía Inglesa, III Región, Chile; PB corresponde a la estación de registro de las variables temperatura, oxígeno y abundancia fitoplanctónica. (B) Dirección e intensidad de las corrientes en Bahía Inglesa según Uribe et al. (1995).

(A) Study area. Location of stations E1 to E5 where collectors were placed in Bahia Inglesa, III Region, Chile; $\mathrm{PB}$ is the station at which temperature, oxygen and phytoplankton abundance were sampled. (B) Direction and intensity of currents in Bahía Inglesa after Uribe et al. (1995). cultivos se trasladaron en cuelgas de dos unidades debidamente etiquetadas a cada una de las estaciones de la bahía, suspendiéndose los colectores a $10 \mathrm{~m}$ de profundidad, en líneas madres instaladas a $4 \mathrm{~m}$ bajo la superficie.

\section{Muestreo en colectores}

Para determinar el número y tamaño de semillas por colectores de cada una de las poblaciones se utilizó la metodología de Uriarte et al. (1996). Para ello, cada 30 días fueron extraídos dos colectores con semillas de cada una de las estaciones de pre-engorda, los cuales fueron transportados dentro de bolsas hasta la unidad de investigación de la empresa, donde se procedió a sacar la semilla fijada, la que fue contada y medida bajo un microscopio estereoscópico Olympus BH2.

\section{Análisis bacteriológico}

Para determinar los cambios en la bacterioflora asociadas a larvas de diferentes orígenes, se analizaron bacteriológicamente larvas de ojo, postlarvas y juveniles. En el caso de las primeras, se tomó una muestra de larvas de 17 días de edad provenientes de los centros de CMI y Guayacán, las cuales fueron lavadas repetidas veces con solución salina estéril y concentradas en un vaso precipitado con $9 \mathrm{ml}$ de solución salina marina (Austin 1988). Posteriormente, las larvas fueron homogeneizadas con un Tissue-Tearor ${ }^{\mathrm{TM}}$ durante $30 \mathrm{seg}$ y realizando las diluciones apropiadas fueron sembradas en placas de Triptone Soya Agar (TSA, Oxoid) suplementada con $2 \% \mathrm{NaCl}$ y Thiosulphate-Citrate-Bile Salt-Sucrose Agar (TCBS, Oxoid) e incubadas a $20^{\circ} \mathrm{C}$ durante una semana y $72 \mathrm{~h}$, respectivamente. Utilizando la misma metodología descrita anteriormente se realizó el muestreo bacteriológico de las post-larvas.

El análisis microbiano de los juveniles durante los 3 meses de pre-engorda, se realizó cada 30 días. Para ello, se extrajeron al azar 15 semillas de los colectores ubicados en los long-line de cada una de las estaciones, las semillas se colocaron en bolsas de Stomacher estériles y transportadas inmediatamente al laboratorio. Después de lavar las semillas repetidamente con agua de mar estéril, se procedió a separar las partes blandas de cada una de ellas, lavándolas con solución salina marina estéril y concentrándolas en bolsas estériles de Stomacher con $9 \mathrm{ml}$ de solución salina marina. Las bolsas con las partes blandas se homogeneizaron en un Stomacher Lab-Blender 80 durante $1 \mathrm{~min}$. El análisis bacteriológico se 
realizó tomando muestras de $1 \mathrm{ml}$ del homogeneizado y efectuando diluciones apropiadas se sembraron en placas de TSA y TCBS, para finalmente ser incubadas a $20{ }^{\circ} \mathrm{C}$ durante una semana y $72 \mathrm{~h}$, respectivamente. Paralelamente, al registro de las variables abióticas y bióticas se recogieron en la estación $\mathrm{PB}$ muestras de agua de $10 \mathrm{~m}$ de profundidad, las cuales realizando diluciones apropiadas se sembraron en placas de TSA y TCBS, para finalmente ser incubadas a $20{ }^{\circ} \mathrm{C}$ durante una semana y $72 \mathrm{~h}$, respectivamente.

\section{Caracterización y aislamiento de vibrionáceas}

Para determinar la fluctuación de los Vibrio spp. en la bacterioflora asociada a post-larvas, se aislaron desde las colonias crecidas en placas de TCBS las diferentes muestras de semilla y agua de mar. Luego, se procedió a agrupar las cepas de acuerdo a la población de origen y estación de pre-engorda, caracterizando los diferentes morfotipos crecidos en TCBS y aislando los morfotipos predominantes. Se aislaron un total de 120 cepas, las cuales se examinaron microscópicamente mediante tinción Gram y en sistemas miniaturizados Api20E (Hansen \& Sorheim 1991).

\section{Análisis estadísticos}

Para evaluar la influencia de los factores origen de las post-larvas y localización de los colectores sobre la sobrevivencia después de 90 días, se utilizó un análisis de varianza de dos vías, previa transformación de los datos mediante la función angular, la cual normaliza variables en proporciones o porcentajes (Sokal \& Rohlf 1980). La prueba de comparación múltiple de Tukey permitió discernir las estaciones que eran diferentes entre sí. Para mayores detalles respecto al efecto ambiental sobre la sobrevivencia se estimó la tasa de mortalidad diaria como $\mathrm{N}=\mathrm{N} 0 \mathrm{e}^{-\mathrm{zt}}$, donde $\mathrm{N}$ es la abundancia numérica (individuos/colector), N0 la abundancia inicial, t el período de tiempo (días) y z la tasa diaria de mortalidad (1/días). La variable z se estimó en dos réplicas para los períodos 30, 60 y 90 días. Estos valores de acuerdo al origen y localización de colectores se compararon mediante un ANOVA de dos vías sin transformación de datos y presumiendo un comportamiento normal de la variable $\mathrm{z}$.

La comparación de heterótrofas y vibrionáceas entre las localizaciones de los colectores y el origen de las semillas se realizó mediante ANOVA de dos vías sin transformación de datos. Como criterio de significación estadística se utilizó un alfa de 0,05 .

Después de 90 días en la bahía, una potencial divergencia en los caracteres cualitativos del conjunto de vibrionaceas en función de su origen inicial (CMI o Guayacán) se estudió mediante análisis exploratorio de conglomerados y posterior análisis de componentes principales (ACP). Para ello se utilizó la información respecto a la respuesta frente a 22 pruebas bioquímicas, de la cual se obtuvieron 35 fenotipos a partir de las 120 cepas aisladas de Vibrio spp. Para el análisis de conglomerados se utilizó la distancia euclidiana con enlace de centroíde simple. Para la técnica de ACP, se construyó una matriz de covarianza y estimaron dos factores, cuyos componentes se estandarizaron y rotaron mediante la función varimax. Estos factores se les estimó su contribución porcentual a la varianza total y sus valores se graficaron para analizar un eventual agrupamiento de las distintas cepas.

\section{RESULTADOS Y DISCUSIÓN}

Los resultados de la sobrevivencia de semillas durante los tres primeros meses de engorda para cada estación de cultivo se muestran en la Fig. 2. Estos demuestran que los colectores ubicados en las estaciones E1, E2 y E3 presentan mejores sobrevivencias, fluctuando entre 47,26 a 5,81\%. El análisis estadístico de los resultados de sobrevivencia obtenidas con las semillas de ambas poblaciones para cada estación, demostró que las estaciones E4 y E5 son sectores no apropiados para la instalación de colectores (Tabla 1). Al evaluar la variable origen de las larvas se determinó que los organismos provenientes de Guayacán después de los 90 días de cultivo en cada una de las estaciones alcanzaron siempre sobrevivencias más altas.

La alta mortalidad detectada en las estaciones E4 y E5 podría tener su explicación en lo descrito por Uribe \& Castillo (1982); Uribe y Neshyba (1983) y Uribe et al. (1995) para la circulación de la corriente en la bahía (Fig. 1B). Ellos detectaron un flujo de entrada de la corriente que es pobre en biomasa fitoplantónica, debido a la introducción hacia la costa de aguas oceánicas más cálidas y pobres en nutrientes, coincidente con las estaciones E4 y E5. Después, la corriente se bifurca produciendo un área de retención que concuerda con las estaciones de mejor sobrevivencia (E1, E2 y E3). Sin embargo, los análisis cuantitativos de fitopláncton realizados en la estación ubicada en el centro de la bahía, se caracterizaron por ser homogéneos alcanzando concentraciones prome- 


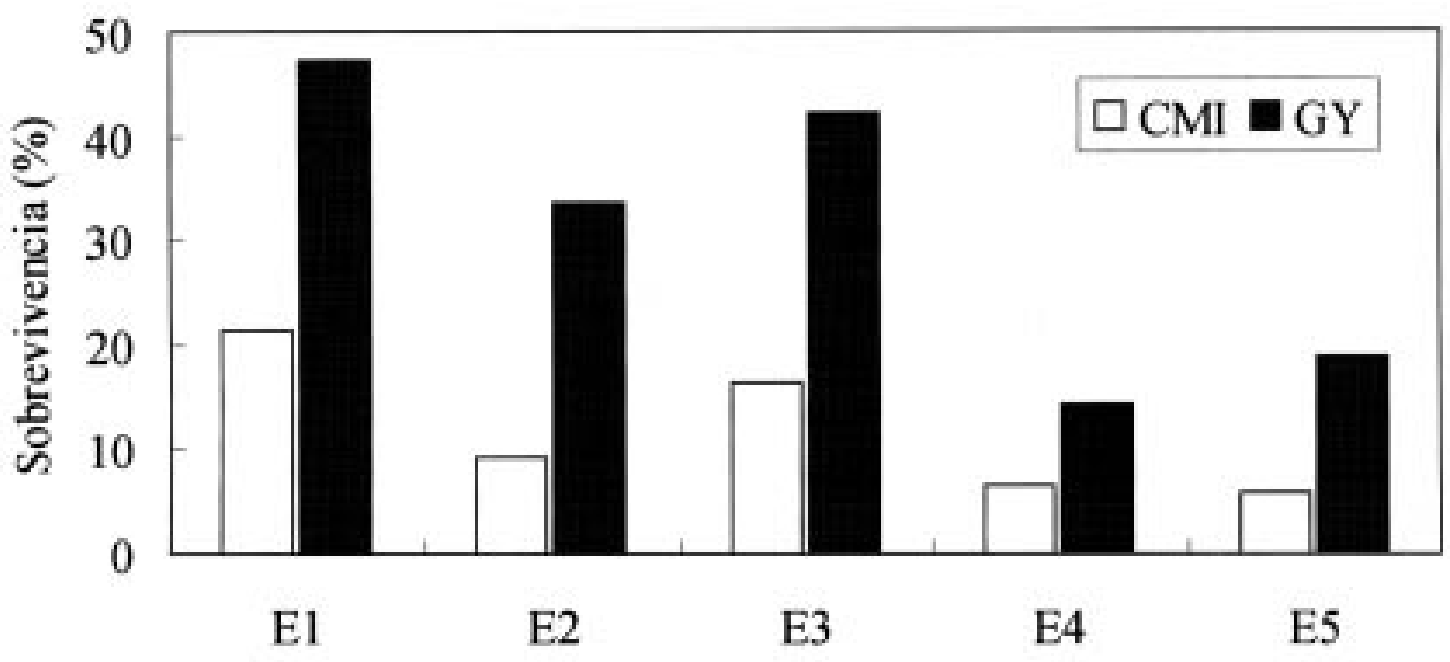

\section{Estación}

Fig. 2: Sobrevivencia después de 90 días de pre-engorda en cada una de las estaciones de cultivo de la semilla de ostión producida en "hatchery" de Cultivos Marinos Internacionales S.A. y Cultivos Guayacan. Los puntos E1, E2, E3, E4 y E5 corresponden a las estaciones indicadas en la Fig. 1.

Survival after 90 days of pre-fattening at each of the stations where scallop seed from the Cultivos Marinos Internacionales and Cultivos Guayacan were cultured. Points E1 through E5 same as in Fig. 1.

dio de $1,5 \times 10^{5}$ células $\mathrm{ml}^{-1}$. Probablemente, en el área de retención la concentración de partículas alimentarias es mayor que en las estaciones ubicadas en la entrada de la bahía. No obstante, se necesitan muestreos de alta frecuencia en cada una de las estaciones utilizadas en el presente estudio, con el objeto de entender la dinámica biológica y física de la bahía.

Con respecto a la mayor sobrevivencia de las semillas originarias de Guayacán en contraste a las producidas en CMI, indicarían que las primeras serían más resistentes a presiones biológicas o ambientales que producen los descensos de la sobrevivencia. Probablemente, un factor importante a considerar es el desarrollo en cultivos Guayacán de la etapa larvaria sin la utilización de antibióticos, generando una post-larva menos susceptibles a los cambios ambientales producidos al momento de transferir las larvas desde el "hatchery" al medio ambiente acuático. Diversos autores señalan que el continuo uso de quimioterapéuticos causa una alteración del equilibrio natural de bacterias aumentando la población bacteriana en el cultivo como también la selección de patógenos resistentes y de esta forma aumentaría la susceptibilidad de los organis-

Prueba de Rangos Múltiples realizada sobre la sobrevivencia medida después de 90 días de pre-engorda en cada una de las estaciones de cultivo. La significancia estadística corresponde

$$
\text { a } \alpha=0,05
$$

Multiple range test carried out on survival after 90 days of pre-fattening at each of the culture stations. Statistical significance at $\alpha=0.05$

\begin{tabular}{cccc}
\hline Estación & Número de muestras & Promedio & Grupos \\
\hline E4 & 4 & $* 374,00$ & $\mathrm{X}$ \\
E5 & 4 & $* 440,25$ & $\mathrm{X}$ \\
E2 & 4 & 761,75 & $\mathrm{XX}$ \\
E3 & 4 & 1069,50 & $\mathrm{XX}$ \\
E1 & 4 & $* 1253,00$ & $\mathrm{X}$ \\
\hline
\end{tabular}

(*) Denota la existencia de diferencias estadísticamente significativas

Denote statistically significant differences 
mos en la etapa de pre-engorda (Bourne et al. 1989, Kerry et al. 1994). Otro factor a considerar en las altas sobrevivencias de las post-larvas de Guayacán en comparación a CMI es el origen de las larvas, ya que existen estudios que relacionan la sobrevivencia de las distintas etapas de cultivo con el origen de los reproductores (Cochard \& Devauchelle 1993). Estudios comparativos del pre-engorde en el mar de semillas de $A$. purpuratus, obtenidas de reproductores de segunda generación del sur y reproductores llevados desde el norte de Chile, detectaron que la sobrevivencia promedio hasta el primer desdoble (3 meses), fue afectada por el origen de los reproductores observándose una mayor sobrevivencia de las semillas del sur de Chile (Uriarte et al. 1996).

El tamaño de las semillas después de 90 días de colocados los colectores en el mar, fluctuó entre $9,7 \pm 1,2$ a $15,4 \pm 2,6 \mathrm{~mm}$, no observándose diferencias de crecimiento entre el origen de las semillas y la localización de los colectores (Fig. $3)$. Estos valores promedios son superiores a los 8,5 $\mathrm{mm}$ comúnmente reportados para $A$. reproductores no influye sobre el crecimiento, pero sí en la sobrevivencia (Cochard \& Devauchelle 1993). Estudios realizados por Page \& Ricard (1990) demostraron que en Mytilus edulis el crecimiento está estrechamente relacionado con la composición específica del fitoplancton. Winter (1978) realizó una revisión crítica de los factores que intervienen en la alimentación de moluscos bivalvos, poniendo en evidencia que una alta concentración de alimento no es sinónimo de un mejor crecimiento y que incluso, podría ser sinónimo de una alta tasa de biodeposiciones. No obstante, es imprescindible señalar que estudios de calidad de producción primaria y fitopláncton en la bahía son escasos, contando sólo con los informes mensuales confeccionados por la unidad de investigación de CMI y el estudio de alta frecuencia realizado por Uribe (1989), el cual muestra en la época de verano e invierno una alta heterogeneidad de las poblaciones fitoplanctónica.

El análisis cuantitativo de heterótrofas totales en las larvas de ojo provenientes de ambos centros de cultivos no mostraron diferencias estadísticas significativas $(\mathrm{P}>0,05)$ oscilando entre 121

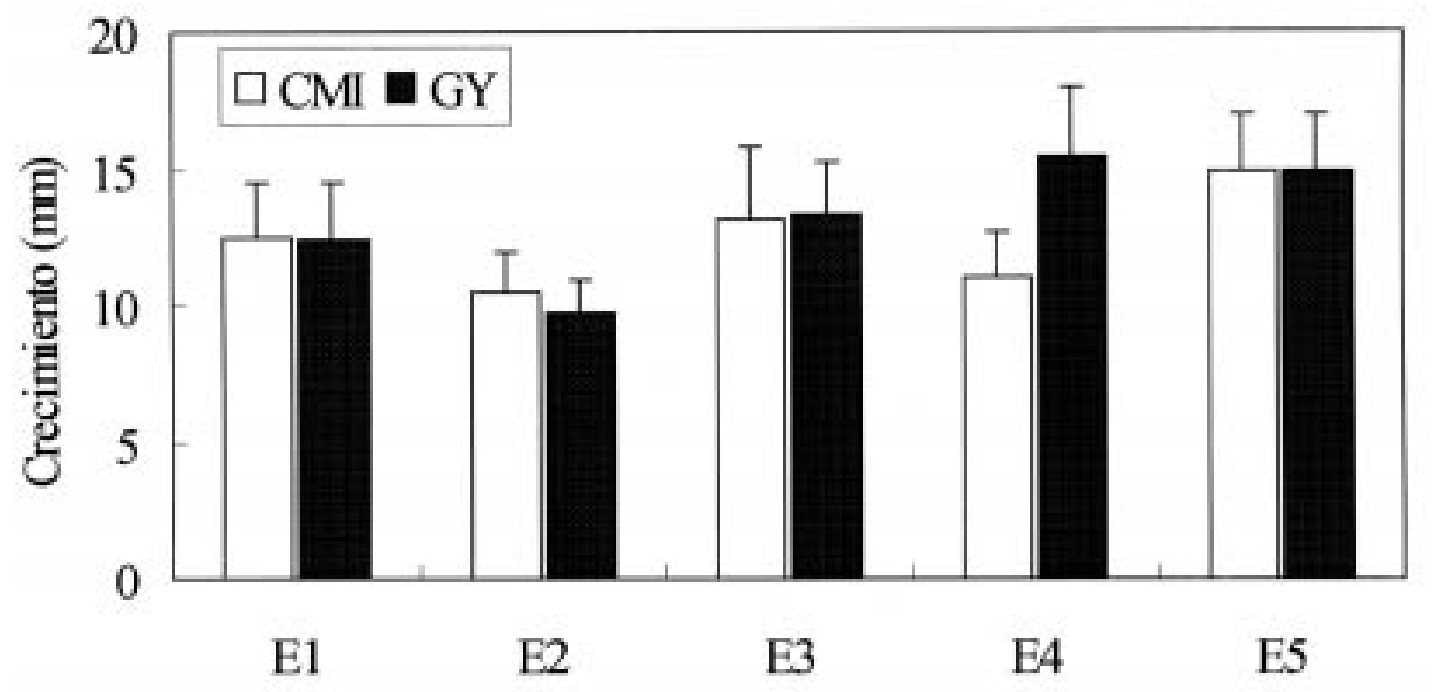

\section{Estación}

Fig. 3: Crecimiento después de 90 días de pre-engorda en cada una de las estaciones de cultivo de la semilla de ostión producida en "hatchery" de Cultivos Marinos Internacionales S.A. y Cultivos Guayacán. Los puntos E1, E2, E3, E4 y E5 corresponden a las estaciones indicadas en la Fig. 1.

Growth after 90 days of pre-fattening at each of the stations where scallop seed from the companies cited in Fig. 2 were cultured. Points E1 through E5 same as in Fig. 1.

purpuratus a los tres meses de cultivo (Akaboshi \& Illanes $1983^{2}$, Avendaño \& Cantillanez 1989). Estudios realizados en Pecten maximus, han detectado que no hay diferencias en crecimientos entre larvas nativas y transplantadas, lo que demostraría que la historia previa de los
2 AKABOSHI S \& JE ILLANES (1983) Estudio experimental sobre la captación, pre-cultivo y cultivo, en ambiente natural de Chlamys (Argopecten) purpurata, Lamarck 1819, en la Bahía de Tongoy, IV Región, Coquimbo. Simposio Internacional de Acuacultura, Chile: 233-251. 
\pm 8 y $86 \pm 27$ CFU larva ${ }^{-1}$. No obstante, después de siete días de cultivo de las post-larvas se detectó en la población de CMI un incremento bacteriano del $38,8 \%$ en los recuentos de heterótrofas totales. Este rápido incremento de la flora bacteriana en las larvas de CMI podría deberse a que en el estado de post-larvas (proceso de fijación) no se adicionó quimioterapéuticos al sistema, lo cual podría gatillar la colonización bacteriana.

Con respecto a la carga de bacterias heterótrofas en semillas durante los tres meses de pre-engorda, los resultados mostraron que a los 60 días de cultivo un incremento significativo $(\mathrm{P}<0,05)$ en los niveles de heterótrofas en las semillas de CMI alcanzando valores cercanos a $10^{6} \mathrm{CFU}$ semilla ${ }^{-1}$
(Fig. 4A). Este incremento bacteriano se produce coincidentemente con un drástico descenso de la abundancia fitoplantónica y aumento de la temperatura en aproximadamente $3{ }^{\circ} \mathrm{C}$ (Fig. 5). Sin embargo, esta proliferación bacteriana no fue detectada en las semillas provenientes de Guayacán, la cual se mantuvo estable durante todo el cultivo variando entre $2 \times 10^{2}$ y $1,4 \times 10^{4}$ CFU semilla ${ }^{-1}$ (Fig. 4B). Es importante destacar que durante este período (60 días) los niveles de heterótrofas presentes en el agua circundante de la bahía fueron mayores a la carga normal de la bahía $\left(2 \times 10^{2} \mathrm{CFU} \mathrm{ml}{ }^{-1}\right)$, detectándose valores de

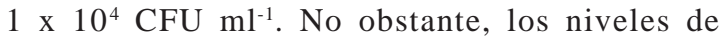
Vibrio spp. se mantuvieron estables con valores
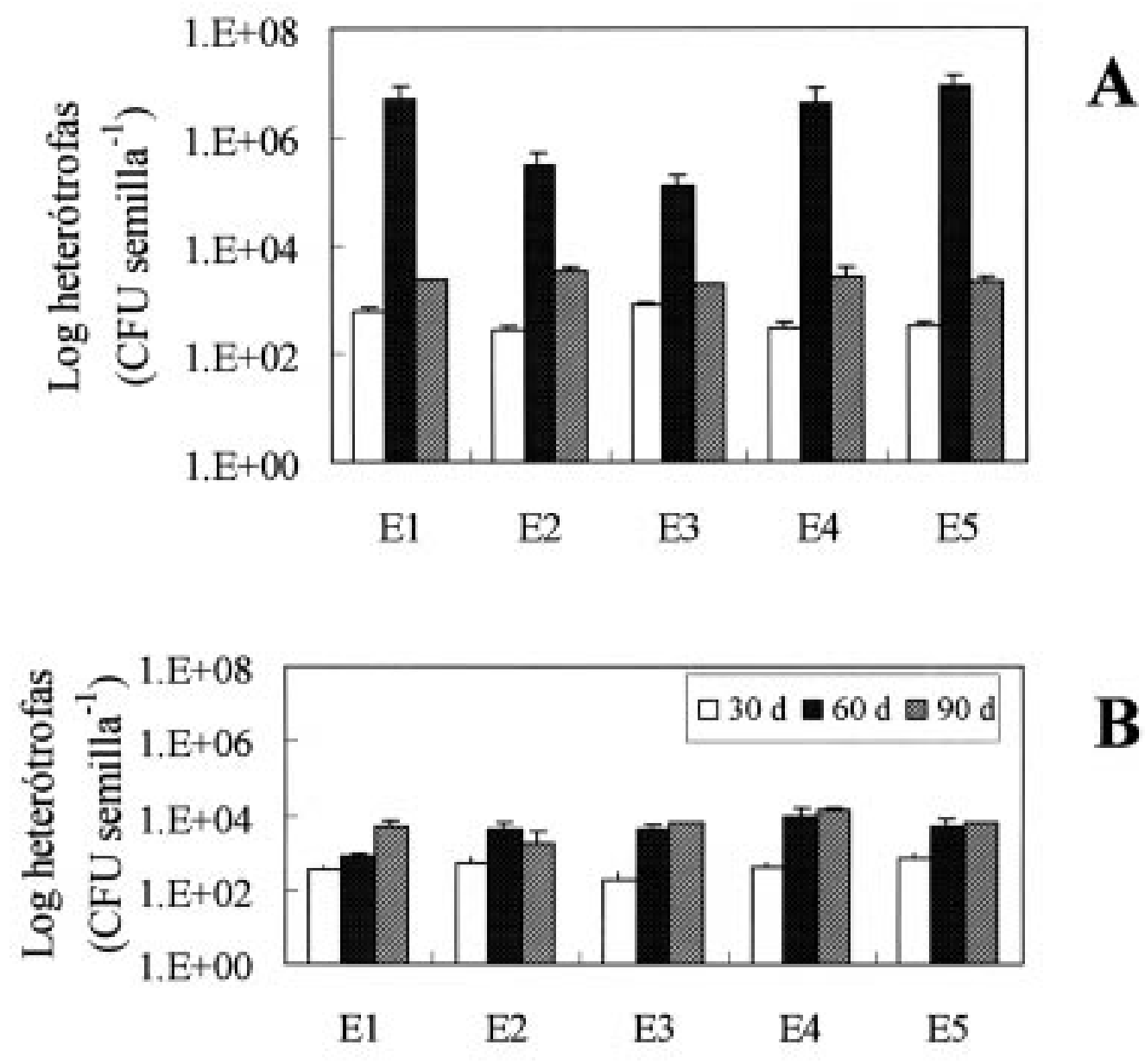

\section{Estación}

Fig. 4: Recuento de heterótrofas totales en semillas de A. purpuratus provenientes de (A) CMI y (B) Guayacan durante los 30, 60 y 90 días de cultivo en Bahía Inglesa. Los puntos E1, E2, E3, E4 y E5 corresponden a las estaciones en las cuales fueron colocados los colectores. Las líneas verticales indican una desviación estándar.

Counts of total heterotrophic bacteria in seed of A. purpuratus from (A) CMI and (B) Guayacan over 30,60, and 90 days of culture in Bahía Inglesa. Points E1 through to E5 refer to stations where collectors were placed. Vertical lines represent one standard deviation. 

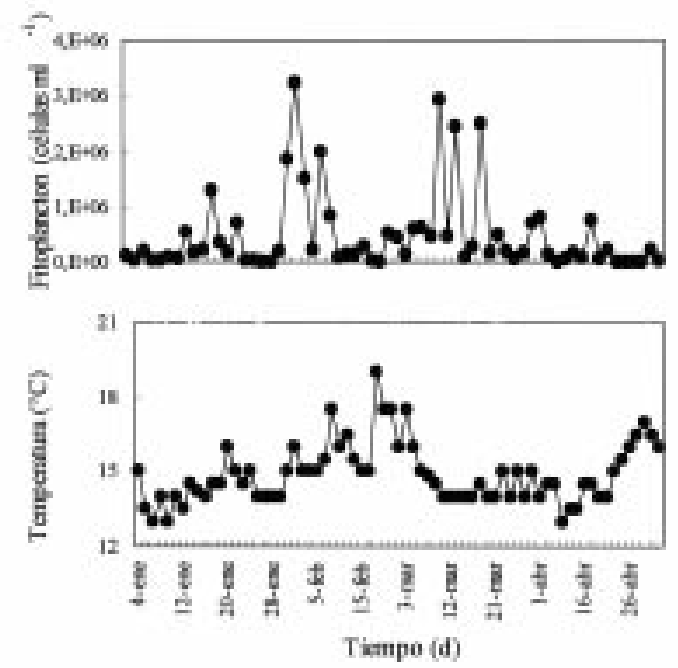

Fig. 5: Registros de la variación de la biomasa fitoplanctónica y temperatura en el centro de la bahía (estación PB) a 10 m de profundidad desde enero a marzo de 1999.

Records of variation in phytoplankton biomass and temperature at the center of the bay (PB) at $10 \mathrm{~m}$ depth from January to March 1999.

promedios de $10^{2} \mathrm{CFU} \mathrm{ml} l^{-1}$. Cabe destacar que los análisis estadísticos no mostraron diferencias significativas entre carga bacteriana y las estaciones en las cuales se ubicaron los colectores. Similares resultados fueron obtenidos en los recuentos de Vibrio spp. de las dos poblaciones de post-larvas en las cinco estaciones.

Probablemente el incremento de bacterias se debió al incremento de la temperatura del agua de mar y el descenso en la producción primaria, dos variables que inciden en la proliferación bacteriana en el medio marino (Colwell 1988, Farmer 1992, Holt et al. 1994). Abarzua et al. (1995), señala que el incremento bacteriano en ambientes acuáticos se debe a la oferta de carbono proveniente del fitoplancton muerto, principal fuente de materia orgánica para las bacterias heterótrofas. Diversos estudios han demostrado que un gran porcentaje de la productividad bacteriana proviene de los productos de excreción del fitoplancton (Azam et al. 1983, Iturriaga \& Zsolnay 1983). Por esta razón, es de esperar un incremento de la carga bacteriana en las semillas de $A$. purpuratus, en consideración a la conducta alimentaria y a la capacidad de bioacumulación de estos organismos (Plusquellec et al. 1983, Prieur et al. 1990). El aumento de heterotrofas registrado en las larvas provenientes de CMI, podría deberse a la carencia de una microflora establemente asociada a esta, lo cual facilitaría la rápida colonización de una microflora transitoria u oportunistas, que corresponde a las bacterias que están de paso por el organismos (Moriarty 1990).

La presencia de Vibrio spp. en las larvas de ojo y post-larvas de ambos cultivos, fue baja alcanzando un $2 \%$. No obstante, después de 30 días de haber sido transferidas al mar se observa un incremento de vibrionaceas alcanzando en todas las estaciones valores ca. $30 \%$ a excepción de la estación E4 (ca. $4 \%$ ). Al finalizar el período de pre-engorda (90 días) todas las poblaciones alcanzaron porcentajes similares de Vibrio spp., los cuales indican que estos se constituyen en bacterioflora residente de las larvas, como ha sido demostrado por Colwell (1984). Estudios realizados en Crassostrea virginica y Mercenaria campechiensis demuestran, al confinar ambas especies a diferentes temperaturas y tiempos de cultivo que la concentración de todos los grupos bacterianos se incrementan significativamente con excepción de Vibrio spp. los cuales se muestran estables (Hood et al. 1983).

El análisis cualitativo de la microflora asociada a las post-larvas provenientes de CMI y Guayacán reveló la presencia de bacterias Vibrio spp. durante los tres meses de cultivo (Fig. 6). Esta presencia constante de Vibrio spp. en $A$. purpuratus en cada uno de los estados de desarrollo fue descrita por Riquelme et al. (1994). No

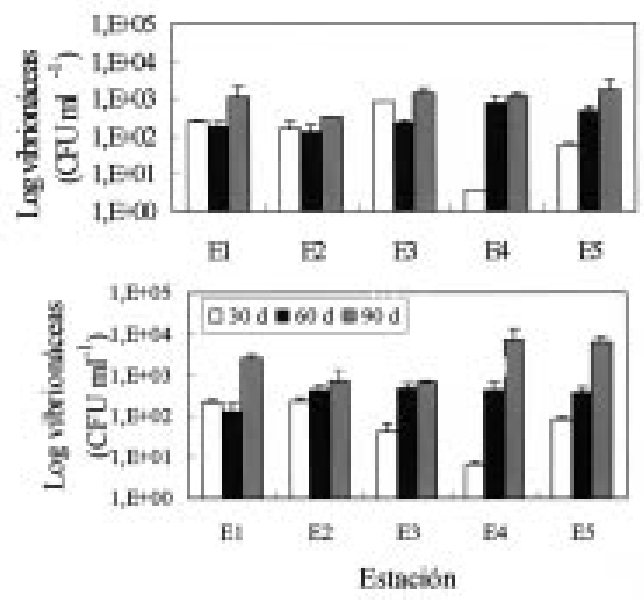

A

Fig. 6: Recuento de vibrios totales en semillas de A. purpuratus provenientes de (A) CMI y (B) Guayacán, durante los 30, 60 y 90 días de cultivo en Bahía Inglesa. Los puntos E1, E2, E3, E4 y E5 corresponden a las estaciones en las cuales fueron colocados los colectores. Las líneas verticales indican una desviación estándar.

Counts of total vibrios in seed of A. purpuratus originating at (A) CMI and (B) Guayacan over 30, 60 and 90 days in Bahía Inglesa. Points E1 trough E5 refer to stations where collectors were placed. Vertical lines represent one standard deviation. 
obstante, es importante destacar que el incremento de Vibrio spp. en las post-larvas de las estaciones E4 y E5 de ambos cultivos es gradual, alcanzando valores similares a las otras estaciones después de 60 días de pre-engorda. Es interesante mencionar que después de los primeros 30 días de pre-engorda la sobrevivencia alcanzadas en las estaciones E4 y E5, presentaban valores bajos $(8,65 \%)$ en comparación a las otras estaciones $(33,88 \%)$ permaneciendo estables hasta el desdoble. Por esta razón, no es atribuible las altas mortalidades en las estaciones E4 y E5 con el incremento de Vibrio spp.

El análisis de cluster de 35 fenotipos representativos de los Vibrio spp. encontrados permite diferenciar dos grupos de cepas, las cuales podrían ser divididas en 3 subgrupos (Fig. 7). Si bien en los 3 subgrupos se determinaron la presencia de bacterias proveniente de semillas de CMI y Guayacán, en el subgrupo 1 se observa un predominio de Vibrio spp. de CMI $(69,23 \%)$ y en el subgrupo 2 un predominio de Vibrio spp. provenientes de semillas de Guayacán (83,3\%). Los resultados de componentes principales no detectan diferencias entre las cepas aisladas y el origen de las semillas, observándose dos grupos de cepas (1 y 2), las cuales coinciden con los dos grupos principales del análisis de cluster (Fig. 8). Tanto los resultados de análisis de cluster y componentes principales no revelaron diferencias taxonómicas entre los Vibrio spp. de CMI y Guayacán. Faltaría por esclarecer la incidencia de Vibrio spp. asociados a las semillas en la sobrevivencia de estas, debido a que este grupo bacteriano es el componente principal en la microflora larval y podría cumplir un rol en la sobrevivencia y crecimiento de la semilla, ya sea facilitando la digestión de componentes del fitoplancton por acción de enzimas degradativas, proveyendo de factores de crecimiento y/o faci-

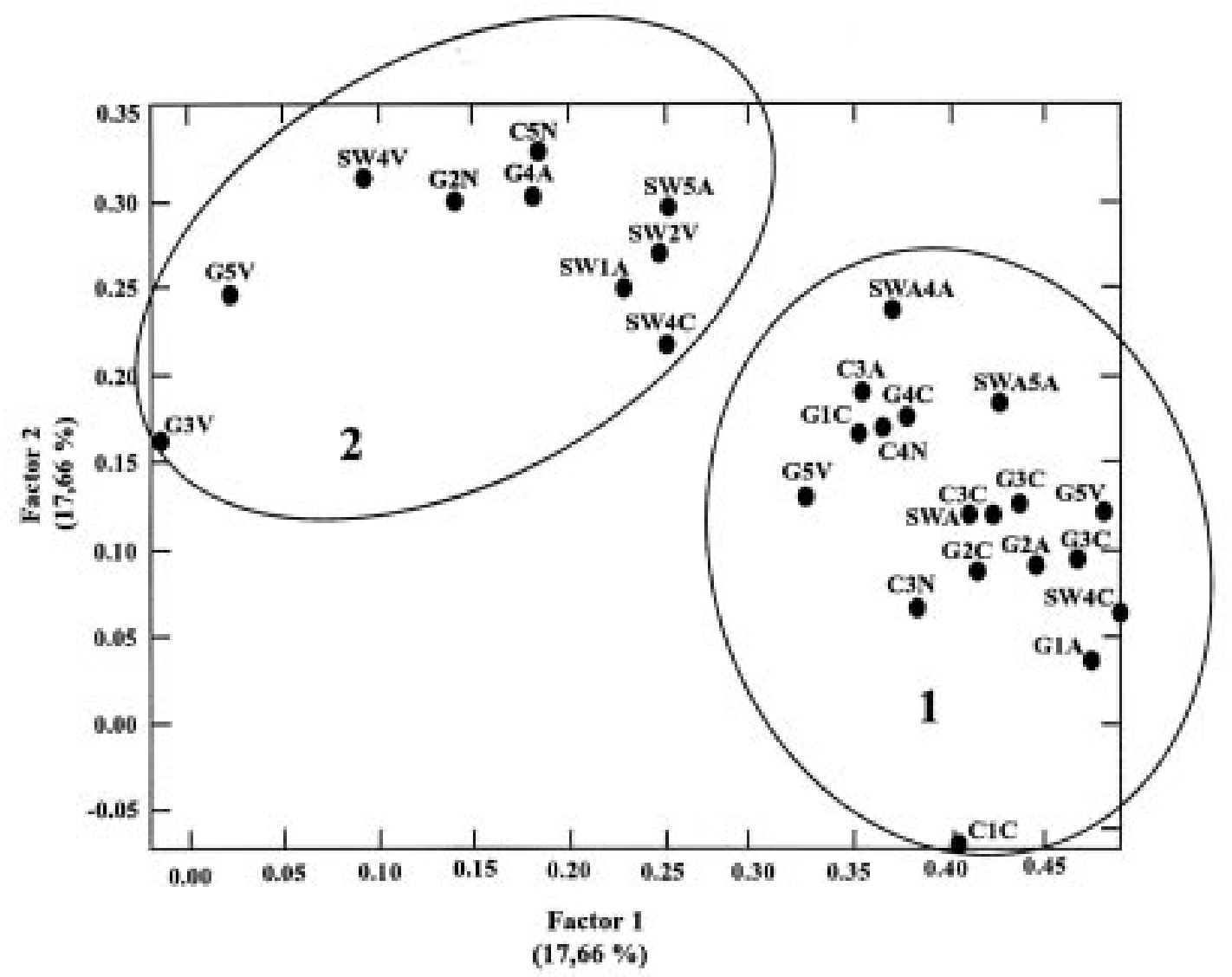

Fig. 7: Análisis de conglomerados de las 35 cepas de Vibrio spp. basado en 20 ensayos bioquímicos. Las cepas identificadas con las letras C y G fueron aisladas desde post-larvas de Cultivos Marinos Internacionales y Cultivos Guayacan, respectivamente. SW corresponde a Vibrio spp. aislados del agua circundante en cada una de las estaciones.

Cluster analysis of 35 strains of Vibrio spp. based on 20 biochemical tests. Strains were isolated from post-larval scallops from Cultivos Marinos Internacionales (C) and Cultivos Guayacan (G). SW refers to Vibrio spp. strains isolated from ambient seawater at each of the stations. 


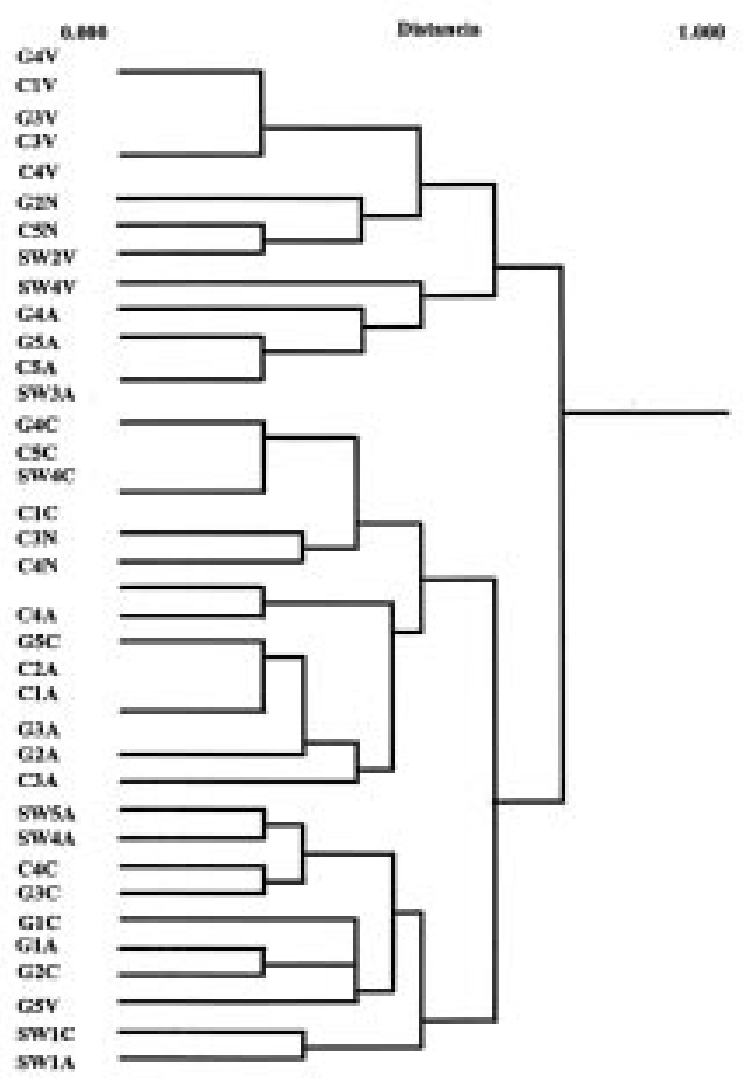

Fig. 8: Análisis de componentes principales de las 35 cepas de Vibrio spp. Las cepas identificadas con las letras $\mathrm{C}$ y $\mathrm{G}$ fueron aisladas desde postlarvas de Cultivos Marinos Internacionales y Cultivos Guayacan, respectivamente. SW corresponde a Vibrio spp. aislados del agua circundante en cada una de las estaciones.

Analysis of principal components of the 35 strains of Vibrio spp. C, G, and SW as in Fig. 7.

litando la absorción de nutrientes (Nicolas et al. 1990, Prieur et al. 1990, Doulliet \& Langdon 1993, 1994).

Los resultados indican que es posible aumentar el número de semillas retornadas, después del primer desdoble colocando los colectores en las estaciones E1 y E3. Además, la sobrevivencia es mejor cuando se utilizan post-larvas de Guayacán.

\section{CONCLUSIONES}

Los resultados del estudio indican claramente que la distribución de las post-larvas en la bahía incide en la sobrevivencia de estas. Además, el origen de las larvas utilizadas en el presente estudio es también un factor determinante en la sobrevivencia. Sin embargo, no se detecta una relación entre el origen y distribución de los colectores con los crecimientos de las post-larvas nativas y transplantadas.

Desde el punto de vista microbiológico se observa que Vibrio spp. llegan a ser un componente predominante en la microflora de ambas poblaciones post-larvales alcanzando valores porcentuales de 53,36 \%. El análisis de componentes principales revela que no hay diferencias entre los Vibrio spp. cultivables de ambos cultivos. No obstante, la microflora residente de las post-larvas de Guayacán es más estable a los incrementos de bacterias en el medio circundante.

\section{AGRADECIMIENTOS}

Este estudio fue financiado por el proyecto FONDEF D97I2033. Los autores agradecen la revisión y comentarios del profesor Ismael Kong y la buena disposición y cooperación prestada por la empresa Cultivos Marinos Internacionales S.A. (III región), otorgando todas las facilidades para la obtención de las muestras. A Fernando Silva y Claudia Navarro por su desinteresada ayuda en el trabajo de terreno y antecedentes proporcionados.

\section{LITERATURA CITADA}

ABARZÚA M, S BASUALTO \& H URRUTIA (1995) Relación entre la abundancia y biomasa de fitoplancton heterotrófico en aguas superficiales del Golfo de Arauco, Chile. Investigaciones Marinas (Chile) 23: 67-74.

ANÓNIMO (2000) Desarrollo acuicultor en la IV Región: los frutos de un trabajo conjunto. Aqua Noticias 54: 45-51.

AUSTIN B (1988) Marine microbiology. Cambridge University Press, London, United Kingdom. 221 pp.

AVENDAÑO M \& M CANTILLANEZ (1989) Observación sobre captación de semillas de Argopecten purpuratus (Lamarck, 1819) en la Bahía de Mejillones del sur, Chile. Estudios Oceanológicos (Chile) 8: 51-59.

AVENDAÑO M \& M CANTILLANEZ (1996) Efectos de la pesca clandestina, sobre Argopecten purpuratus (Lamarck, 1819), en el banco de La Rinconada, II Región. Ciencia y Tecnología Marina (Chile) 19: 57-65.

AVENDAÑO M \& M CANTILLANEZ (1997) Necesidad de crear una reserva marina de ostiones en el banco de La Rinconada (Antofagasta II Región, Chile). Estudios Oceanológicos (Chile) 16: 109-113.

ÁVILA M, M SEGUEL, H PLAZA, E BUSTOS \& R OTAÍZA (1994) Estado de situación y perspectivas de la Acuicultura en Chile. Informe CORFO-IFOP 94/1. 170 pp.

AZAM F, T FENCHEL, J FIELD, J GRAY, L MEYER-REIL \& F THINGSTAD (1983) The ecological role of watercolumn microbes in the sea. Marine Ecology Progress Series 10: 257-263. 
BOURNE N, CA HODGSON \& JNC WHYTE (1989) A manual for scallop culture in British Columbia. Canadian Technology Report Fish Aquatic Science 19: 64-215.

COCHARD JC \& N DEVAUCHELLE (1993) Spawning, fecundity and larval survival and growth in relation to controlled conditioning in native and transplanted populations of Pecten maximus (L): evidence for the existence of separate stocks. Journal of Experimental Marine Biology and Ecology 169: 41-56.

COLWELL RR (1984) Vibrios in the environmental. John Willey \& Sons, Inc., New York, New York. 621 pp.

COLWELL PL (1988) Organic carbon release by phytoplankton: its composition and utilization by bacterioplankton. Journal Planktonic Research 5: 477493.

COMPENDIO DE ACUICULTURA DE CHILE 1998 (1998) Aquanoticias Internacional. TechnoPress, Santiago, Chile. 244 pp.

DOUILLET P \& C LANGDON (1993) Effects of marine bacteria on the culture of axenic oysters Crassostrea gigas (Thunberg) larvae. Biological Bulletin 184: 36-51.

DOUILLET P \& C LANGDON (1994) Use of probiotic for the culture of larvae of the Pacific oyster (Crassostrea gigas Thunberg). Aquaculture 119: 25-40.

FARÍAS A, I URIARTE \& JC CASTILLA (1998) A biochemical study of the larval and postlarval stages of the Chilean scallop Argopecten purpuratus. Aquaculture 166: 37-47.

FARMER J (1992) The Family Vibrionaceae. En: Balows A, HG Truper, M Dworkin, W Harder \& KH Scheleifer (eds) The prokaryotes: 2938-3011. Springer-Verlag, Berlin, Germany.

HANSEN GH \& R SORHEIM (1991) Improved method for phenotypical characterization of marine bacteria. Journal of Microbiological Methods 13: 231-241.

HOLT JG, NR KRIEG, PH SNEATH, JT STALEY \& ST WILLIAMS (1994) Bergey's manual of determinative bacteriology. Ninth edition. Williams \& Wilkins, Baltimore, Maryland. 787 pp.

HOOD MA, GE NESS, GE RODRICK \& NJ BLAKE (1983) Effects of storage on microbial loads of two commercially important shellfish species, Crassostrea virginica and Mercenaria campechiensis. Applied Enviromental Microbiology 4: 1221-1228.

ITURRIAGA R \& A ZSOLNAY (1983) Heterotrophic uptake and tranformation of phytoplankton extracellular products. Botanic Marine 26: 375-381.

KERRY J, M HIDNEY, R COYNE, D CAZABOM, S NICGBHAINN \& P SMITH (1994) Frequency and distribution of resistance to oxytetracycline in microorganisms isolated from marine fish farm sediments following therapeutic use of oxytetracycline. Aquaculture 123: $43-54$.

LODEIROS CJM \& JH HIMMELMAN (2000) Identification of factors affecting growth and survival of tropical scallop Euvola (Pecten) ziczac in the Golfo de Cariaco, Venezuela. Aquaculture 182: 91-114.
MORIARTY DJ (1990) Interactions of microorganism and aquatic animals, particularly the nutrional role of the gut flora. En: Léser R (ed) Microbiology in poecilotherms: 218-222. Elsevier Science, Publishers B.V., Paris, France.

NAVARRO R, L STURLA, O CORDERO \& M AVENDAÑO (1991) Fisheries and aquaculture: Chile. En: Shumway SE (ed) Scallops, biology, ecology and aquaculture: 1001-1015. Elsevier Science Publisher, New York, New York.

NICOLAS JL, D ANSQUER \& B BESSE (1990) Influence of bacterial flora on performances of larval rearings in marine aquaculture. En: Léser R (ed) Microbiology in poecilotherms: 177-185. Elsevier Science, Publishers B.V., Paris, France.

PAGE HM \& Y RICARD (1990) Food availability as a limiting facto to mussel Mytilus edulis growth in California coastal waters. Fishery Bulletin 88: 677-686.

PLUSQUELLEC A, M BEUCHER \& L GAL (1983) Enumeration of the bacterial contamination of bivalves in monitoring the marine bacterial pollution. Marine Pollution Bulletin 14: 260-263.

PRIEUR D, G MEVEL, JL NICOLAS, A PLUSQUELLEC \& M VIGNEULLE (1990) Interactions between bivalve molluscs and bacteria in the marine environment. Oceanography Marine Biological Annual Review 28: 277-352.

RIQUELME C, P CHAVEZ, Y MORALES \& G HAYASHIDA (1994) Evidence of parental bacteria transfer to larval in Argopecten purpuratus (Lamarck, 1819). Biological Research 27: 129-134.

SOKAL R \& J ROHLF (1980) Introducción a la bioestadística. De Reverte S.A., Barcelona, España. 362 pp.

URIARTE I, A FARÍAS \& C MUÑOZ (1996) Cultivo en hatchery y pre-engorde del Ostión del Norte, Argopecten purpuratus (Lamarck, 1819), en el Sur de Chile. Revista Biología Marina (Chile) 31: 81-90.

URIBE E \& J CASTILLO (1982) Tintínidos indicadores de masa de agua. Investigaciones Marinas (Chile) 10: 15-34.

URIBE E \& S NESHYBA (1983) Phytoplankton pigments from NIMBUS-7 coastal zone color scanner: coastal waters of Chile from $18^{\circ}$ to $40^{\circ} \mathrm{S}$. En: Arana P (ed) Marine resources of the Pacific: 33-40. Ediciones Universidad Católica de Valparaíso, Vaparaíso, Chile.

URIBE T, J OLIVARES, J MORAGA, J ILLANES, J RUTLANT, D BORÉ, J BLANCO, C JÉLVEZ \& G LEDERMANN (1995) Determinación de la capacidad de carga de la Bahía Inglesa (III Región) y Tongoy (IV Región). Informe Final FIP-IT/ 93-28. 130 pp.

UTERMÖHL H (1958) Zur vervollkommung der quantitativen phytoplankton methodik. Mittilungen Internationale Vereinigung Limnologie 9: 1-38.

WINTER JE (1978) A review on the knowledge of suspension feeding in lamellibranchiate bivalves, with special reference to artificial aquaculture systems. Aquaculture 13: $1-33$.

WOLFF M \& E ALARCÓN (1993) Structure of a scallop Argopecten purpuratus (Lamarck, 1819) dominated subtidal macro-invertebrate assemblage in northern Chile. Journal of Shellfish Research 2: 295-304. 